Supplement of Clim. Past Discuss., 10, 2519-2546, 2014

http://www.clim-past-discuss.net/10/2519/2014/

doi:10.5194/cpd-10-2519-2014-supplement

(C) Author(s) 2014. CC Attribution 3.0 License.

(c) (i)

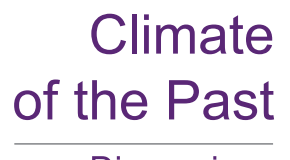

Discussions

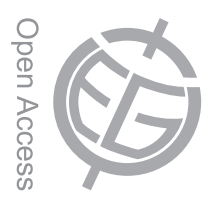

Supplement of

\title{
An abrupt slowdown of Atlantic Meridional Overturning Circulation dur- ing 1915-1935 induced by solar forcing in a coupled GCM
}

P. Lin et al.

Correspondence to: Y. Song (songy@ mail.iap.ac.cn) 
(a) Historical r2

(Sv)

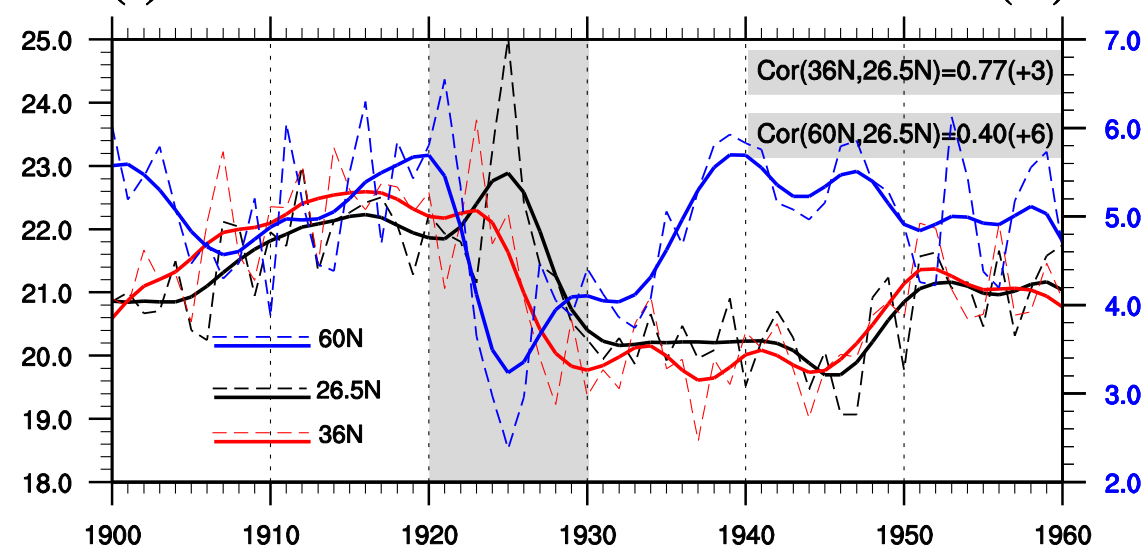

(b) Historical r3

(Sv)

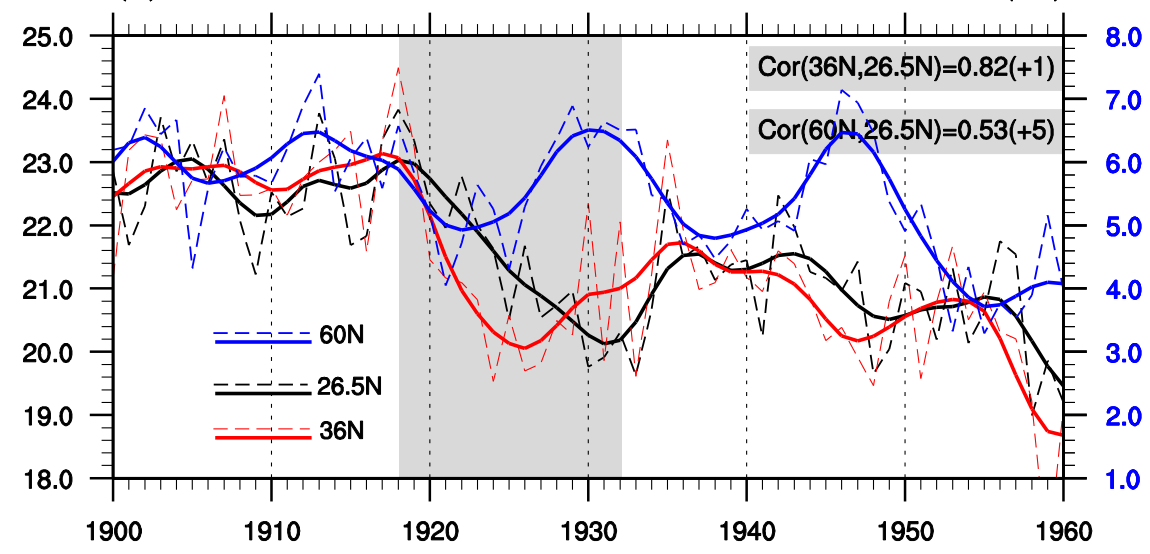

(c) PiControl

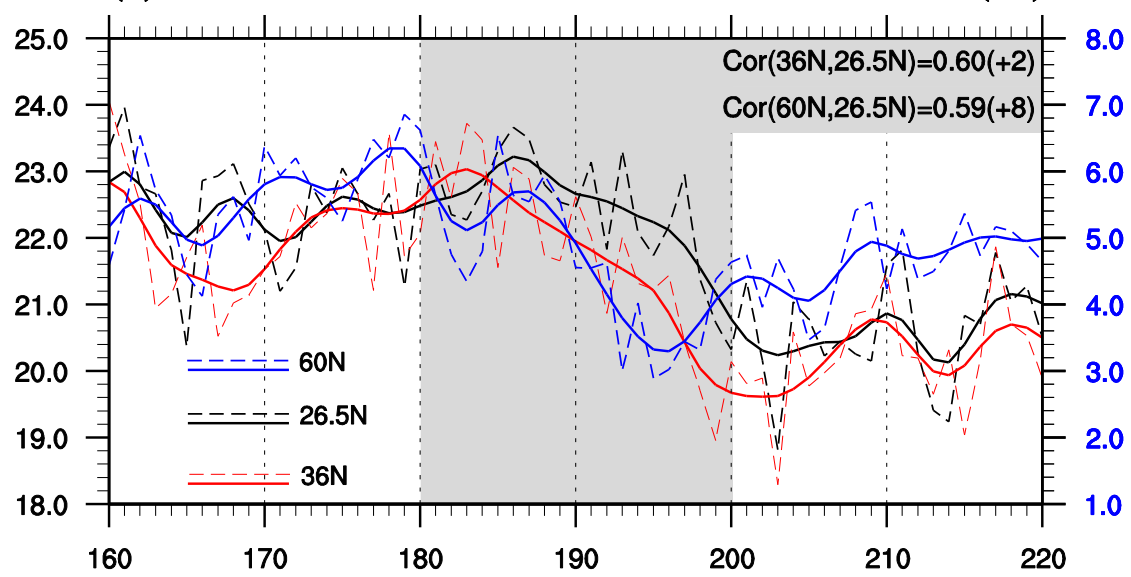

4 


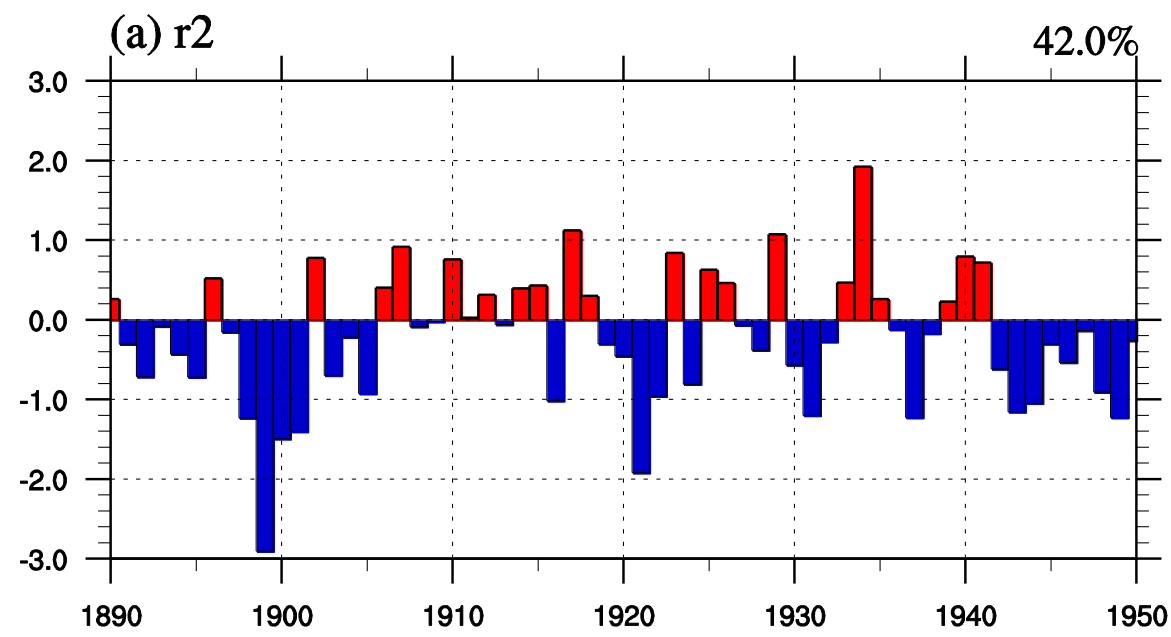

(b) r3

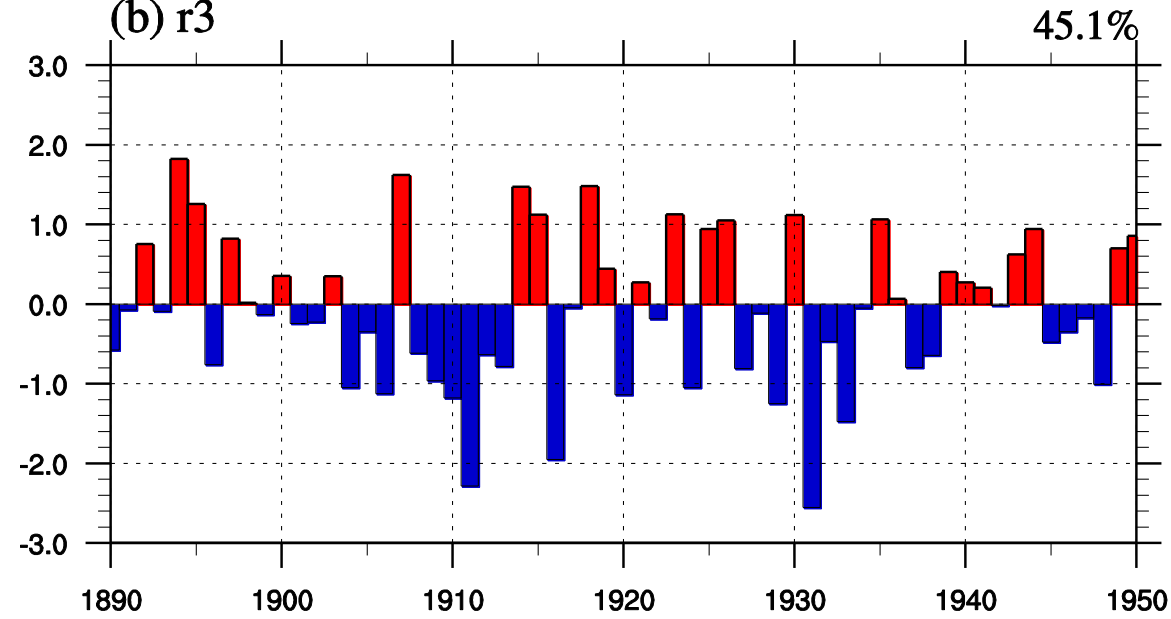

2

(c) PiControl

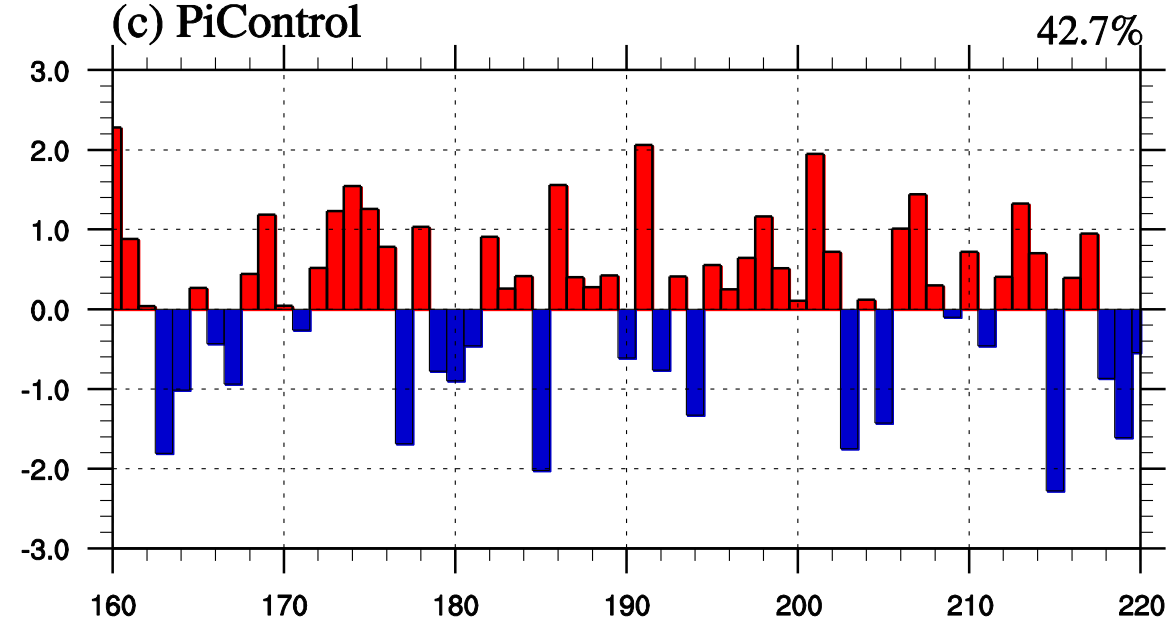

$4 \quad$ Figure S2. The leading multivariate EOF PC of annual mean sea level pressure and wind stress over the North Atlantic region $\left(90^{\circ} \mathrm{W}-40^{\circ} \mathrm{E}\right)$ for other two historical runs (a and b) and PiControl run (c). The percentage of variance explained by the first EOF is shown in the top right corner of each plot. 

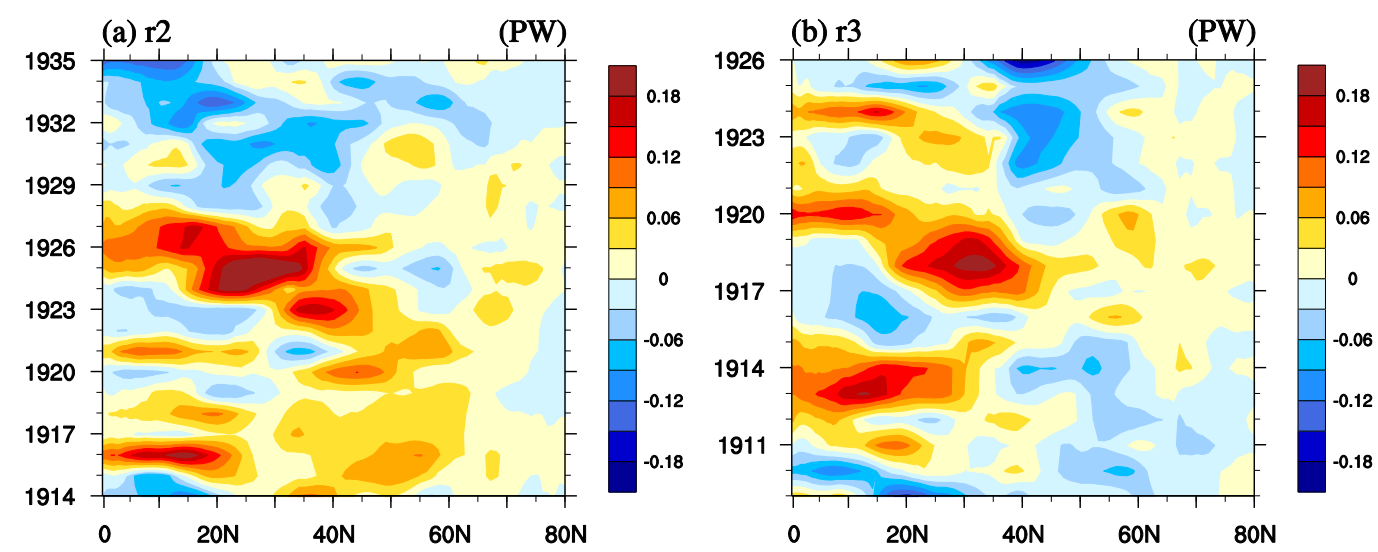

(c) PiControl (PW)

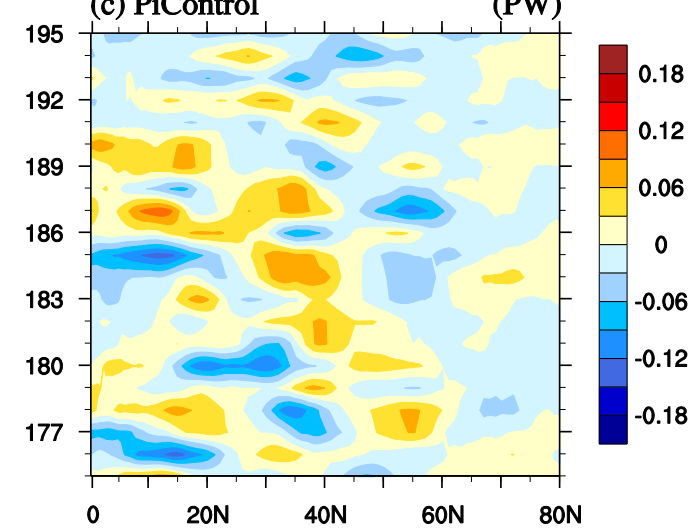

3 Figure S3. Latitude-time diagrams of northward ocean heat transport (PW; $1 \mathrm{PW}=10^{15} \mathrm{~W}$ ). 4 Anomalies are relative to 1880-1900 in the North Atlantic Ocean for other two historical runs (a 5 and b) and PiControl run (c). 


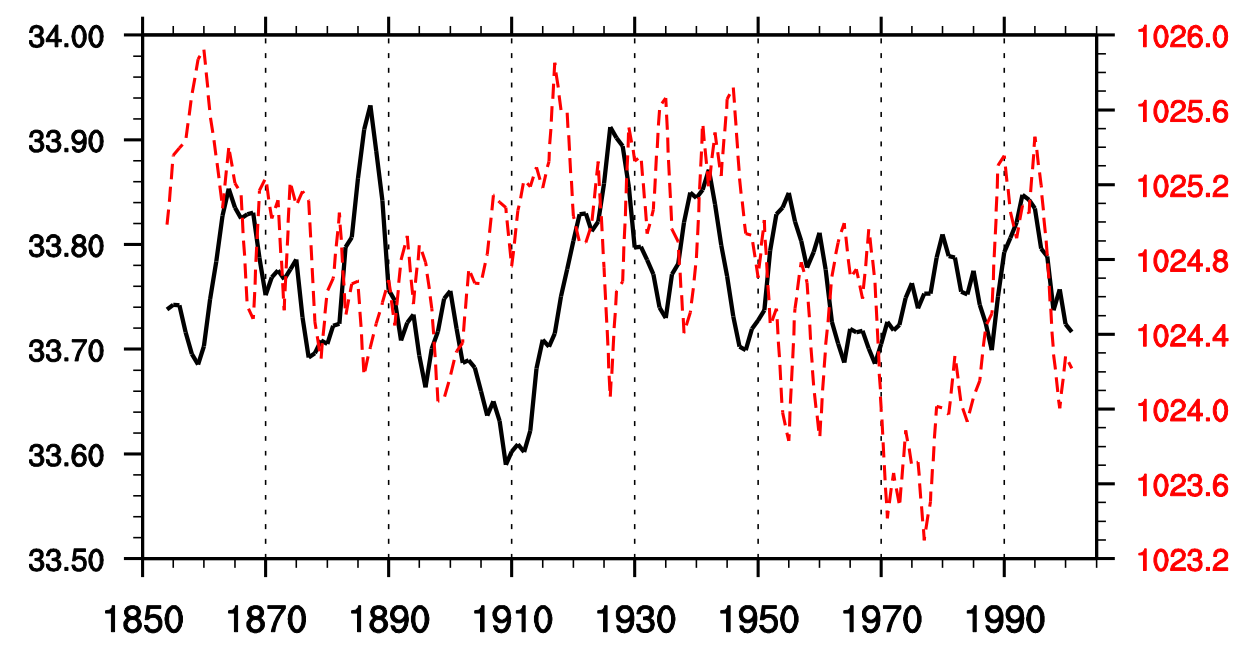

4 Figure S4. The regional $\left(142^{\circ} \mathrm{E}-142.5^{\circ} \mathrm{E}, 27^{\circ} \mathrm{N}-27.5^{\circ} \mathrm{N}\right)$ averaged sea surface salinity (SSS, 5 black line) in the historical run. The regional averaged winter sea level pressure (SLP, red line) 6 over northeast Asia $\left(110^{\circ} \mathrm{E}-130^{\circ} \mathrm{E}, 45^{\circ} \mathrm{N}-60^{\circ} \mathrm{N}\right)$. The results are for the nine-year running mean 7 values. 


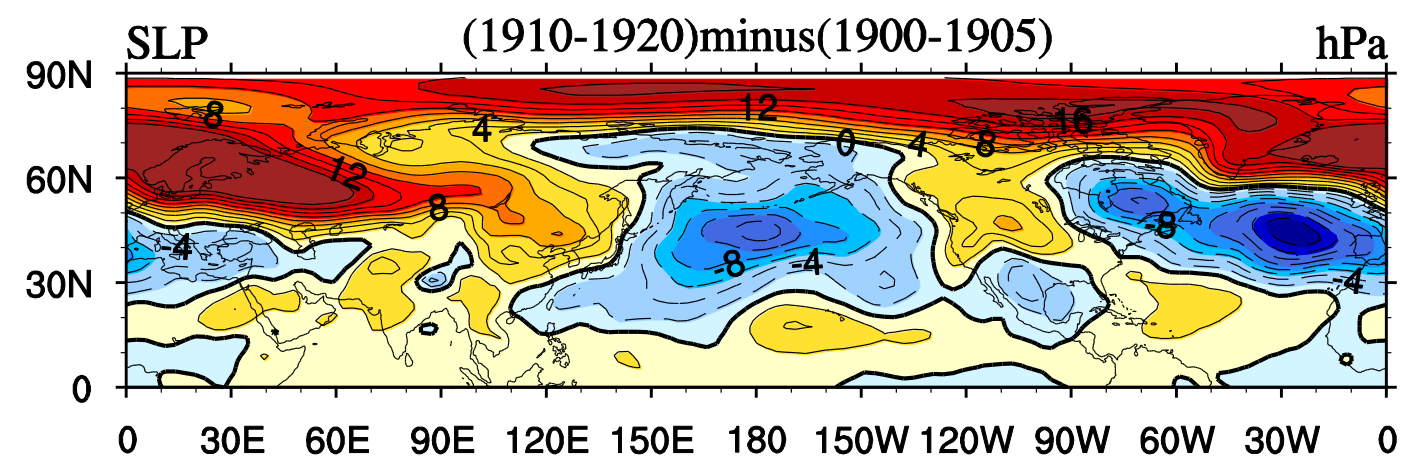

3

4 Figure S5. Sea level pressure (SLP) differences between the periods after (1910-1920) and 5 before (1900-1905) the freshening. 